DOI: https://doi.org/10.24867/15AM04Djuranovic

\title{
ALUMINOTERMIJSKO ZAVARIVANJE ŽELEZNIČKIH ŠINA UZ PRIMENU INOKULANATA
}

\section{THERMITE RAIL WELDING WITH INOCULANTS}

\author{
Ilija Đuranović, Sebastian Baloš, Fakultet tehničkih nauka, Novi Sad
}

\begin{abstract}
Oblast - MAŠINSTVO
Kratak sadržaj- $U$ radu je izvršeno aluminotermijsko zavarivanje šina uz primenu i bez inokulanata. U okviru labaratorijskih ispitivanja sprovedena je ultrazvučna defektoskopija, metalografsko ispitivanje i izvedeno je ispitivanje tvrdoće zavarenog spoja. Kod sva tri uzorka registrovana je veća tvrdoća metala šava u odnosu na kontrolni uzorak. Generalno posmatrano u području metala šava najveću tvrdoću zabeležio je uzorak broj 1 koji sadrži najmanju količinu dodatih nano čestica titan dioksida $\mathrm{TiO}_{2}$ u iznosu od 0,72 g. Osnovni razlog leži u modifikaciji mikrostrukture u smislu nestanka intragranularnog idiomorfnog ferita u modifikovanim uzorcima.
\end{abstract}

Ključne reči: aluminotermijski postupak, nano čestice, karakterizacija materijala

Abstract- In this paper, thermite welding of rails with and without inoculants was performed. Ultrasonic defectoscopy, metallographic analysis and hardness testing of the welds were performed. In all three samples, higher weld metal hardness was measured compared to the control sample. Generally, in the area of weld metal, the highest hardness was recorded in sample number one, which contains the smallest amount of added titanium dioxide $\mathrm{TiO}_{2}$ nanoparticles of 0,72 $\mathrm{g}$. The main reason for this is the modification of microstructure related to the absence of intragranular idiomorphic ferrite in modified specimens.

Keywords: thermite welding, nanoparticles, materials characterization

\section{UVOD}

Zavarivanje predstavlja tehnološki postupak formiranja neraskidivih spojeva, koji su izvedeni uspostavljanjem međuatomskih veza između elemenata uz postojanje procesa difuzije, gde je neprekidnost strukture karakteristika takvih spojeva [1].

Metoda aluminotermijskog zavarivanja je postupak zavarivanja topljenjem, gde se koristi mešavina aluminijumskog praha i oksida gvožđa koji se na visokoj temperaturi, na oko $2500^{\circ} \mathrm{C}$ pretvaraju u aluminijum oksid i železo, odnosno čelik, ukoliko ima prisutnog ugljenika i legirajućih elemenata [2].

Sam termit predstavlja smešu aluminijumskih granula $i$ metalnog oksida. Nakon što se sprovede početno paljenje, termit oslobađa jaku egzotermnu reakciju.

\section{NAPOMENA:}

Ovaj rad je proistekao iz diplomskog rada čiji mentor je bio prof. dr Sebastian Baloš.
Velika količina toplote, koja se oslobađa usled reakcije, omogućava dobijanje tečnog metala, bez korišćenja spoljašnjih izvora energije [3, 4].

U sastav termitne smeše ulazi smeša aluminijuma, ferolegura i oksida gvožđa, gde je cilj da sastav smeše bude podešen na taj način da se nakon završetka procesa zavarivanja sastav metala zavara što manje razlikuje od sastava osnovne šine [5].

Spajanje šina kod ovog procesa obezbeđuje se pomoću rastopa, koji ispunjava kalupnu šupljinu prethodno centriranog kalupa. Tečni čelik nastaje jakom egzotermnom hemijskom reakcijom između oksida železa i aluminijuma, koji ima ulogu redukcionog sredstva [5].

Prednosti procesa uključuju relativnu jednostavnost i brzinu ugradnje, fleksibilnost postupka za zavarivanje svih profila i vrsta šina i ekonomičnost.

Glavni nedostaci ovog postupka su mnogi koraci koje zavarivač u toku procesa rada mora primeniti, kao i uslovi okoline koji mogu rezultirati lošijim performansama zavarivanja. Ove promenljive uključuju stvari kao što su poravnanje krajeva šina, razmak na kraju šine, kvalitet pakovanja kalupa i porcije, trajanje predgrevanja, predgrevanje lončića i preusmeravajućeg čepa, vlaga u vazduhu i kristalizacije mesta zavara [6].

Najpoznatije metode naprednih postupaka aluminotermijskog zavarivanja poput SkV, SoW -5, THR, HPW, SRZ i SKS razvijene su od strane Elektro-termit Gmbh\&Co, jednog od vodećih svetskih proizvođača opreme iz ove oblasti [3].

U okviru izrade master rada izvršeno je eksperimentalno aluminotermijsko zavarivanje šina, pri čemu je korišćen SOW postupak, bez i sa dodatim nanočesticama, u cilju utvrđivanja njihovog uticaja na osobine dobijenog zavarenog spoja.

\section{EKSPERIMENTALNI RAD}

\subsection{Priprema uzoraka}

Osnovni materijal je šina oznake 49E1, prikazana na Slici 1. Nominalni hemijski sastav klase materijala R260 je dat $\mathrm{u}$ tabeli 1 . Za potrebe ovog eksperimentalnog rada aluminotermijskim SOW postupkom zavarivanja dobijeno je ukupno četiri uzorka, gde jedan uzorak predstavlja kontrolni uzorak 0 i prilikom njegove izrade nisu korišćene nanočestice, dok su preostala tri uzorka formirana uz dodatak nanočestica titan dioksida $\mathrm{TiO} 2$. Uzorak 1 sadrži 0,72 g dodatih nanočestica titan dioksida TiO2, uzorak 2 sadrži 2,82 g nano čestica, dok treći uzorak sadrži 4,98 g nanočestica. Količina nanočestica je 
tako odmerena da je sadržaj nanočestica u glavi šine 0,1 ; 0,4 i $0,7 \%$. Nano čestice su bile postavljene $u$ aliminijumsku foliju debljine $0,01 \mathrm{~mm}(10 \mu \mathrm{m})$, mase 0,$15 ; 0,22$ i $0,44 \mathrm{~g}$, koja je vezana bakarnom žicom za keramički čep sa gornje strane kalupa, tako da se nalazi u prostoru koji odgovara mestu gde se nalazi glava šine. Nakon zavarivanja, pristupilo se brušenju glave šine.

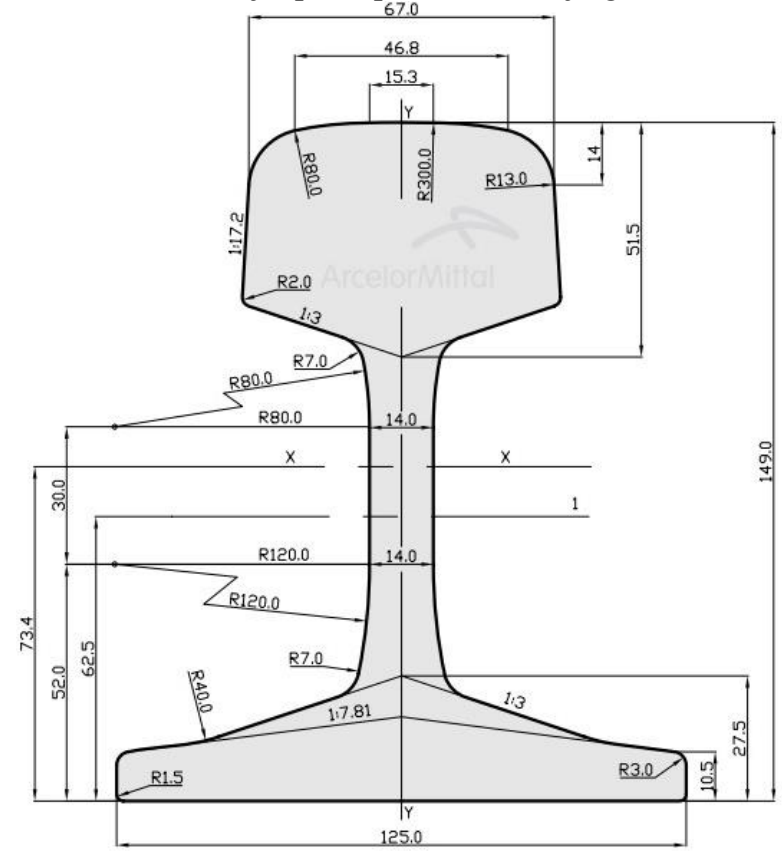

Slika 1 Korišćena šina 49E1 (S49) sa dimenzijama profila [7]

Tabela 1 Hemijski sastav prema EN13674-1:2011, ostatak Fe, u [masenim \%]

\begin{tabular}{|l|l|l|l|l|l|}
\hline $\mathbf{C}$ & $\mathbf{M n}$ & $\mathbf{S i}$ & $\mathbf{P}$ & $\mathbf{S}$ & $\mathbf{N i}$ \\
\hline $0,62-0,8$ & $0,7-1,2$ & $0,15-0,58$ & do 0,025 & do 0,025 & do 0,10 \\
\hline Mo & $\mathbf{A l}$ & $\mathbf{C r}$ & $\mathbf{V}$ & $\mathbf{C u}$ & $\mathbf{N b}$ \\
\hline do 0,02 & do 0,02 & do 0,15 & do 0,13 & do 0,09 & do 0,01 \\
\hline
\end{tabular}

Pre nego što se pristupilo ultrazvučnom ispitivanju šinskih profila, šinski profili su čišćeni krpom i žičanom četkom, kako bi se uklonile masti i grube nečistoće. Nakon toga pre naslanjanje sondi na šinski profil i pre početka ultrazvučne defektoskopije, bilo je neophodno premazati ispitivanu površinu lubrikantom, odnosno ultrazvučnim gelom. Nakon toga uzorak je bio spreman za početak ultrazvučnog ispitivanja.

Nakon ultrazvučnog ispitivanja, isečeni su uzorci dimenzija 10x10x150 mm trakastom testerom sa vrha šine za metalografsku analizu i merenje tvrdoće. Metalografska priprema se sastojala od montiranja, brušenja, poliranja i nagrizanja nitalom (3\% azotne kiseline $\mathrm{HNO} 3$ $\mathrm{u}$ alkoholu).

\subsection{Ultrazvučna ispitivanja}

Primenjena ultrazvučna defektoskopija imala je za cilj otkrivanje defekata, odnosno grešaka u materijalu šine, što se vrši ispitivanjem zapremine zavarenog spoja i zone uticaja toplote. Prilikom ultrazvučnog ispitivanja kontrolnog uzorka, kao i uzoraka sa dodatim nanočesticama titan dioksida $\mathrm{TiO}_{2}$ korišćen je ultrazvučni uređaj tipa UCD-50 IPS. Dozvoljena veličina greške je $5 \mathrm{~mm}$.

\subsection{Metalografska ispitivanja materijala}

Metalografija predstavlja nauku koja se bavi ispitivanjem mikrostrukture, odnosno unutrašnje građe i osobina metala i legura. Mikroskopskim ispitivanjem dobija se potpunija slika o unutrašnjoj građi materijala. Ovakav vid ispitivanja pruža mogućnost da se odredi tip mikrostrukture, udeo određenih mikrokonstituenata, veličina zrna, njihova raspodela, orijentacija, kao i veličina uključaka.

Greške koje narušavaju homogenost strukture, a mogu nastati primenom različitih tehnoloških procesa, mogu se ustanoviti ovim vidom ispitivanja [8]. Uzorci su ispitivani na svetlosnom mikroskopu Leitz Ortoplan.

\subsection{Ispitivanje tvrdoće}

Tvrdoća metala i legura predstavlja otpor koji taj materijal pruža prilikom prodiranja nekog tvrđeg tela. Tvrdoća je indikator čvrstoće materijala, ali se ujedno koristi kao indikator pojave zakaljenja u zoni uticaja toplote. U radu je korišćena metoda po Vikersu, na istim uzorcima koji su korišćeni za metalografska ispitivanja.

Izvršena su po tri merenja tvrdoće sa obe strane osnovnog materijala (OM), u zoni uticaja toplote (ZUT) i u metalu šava (MŠ), na tri mesta: na sredini tri merenja i po tri merenja prema ZUT-u (MŠ1 i 2).

\section{REZULTATI I DISKUSIJA}

\subsection{Ultrazvučna defektoskopija}

Defektoskop, odnosno sonda registrovala je u zavarenom spoju i oko zavarenog spoja (ZUT) minimalne ehoe i šumove, što je znak da nema značajnijih grešaka i nepravilnosti koje bi na bilo kakav način mogle ugroziti postojanost zavarenog spoja.

Mali pikovi, odnosno šumovi koji su zabeleženi na defektoskopu pokazuju da je mikrostruktura povoljna sa stanovišta postojanja grešaka. Pikovi koji se pojavljuju na ovaj način, produkt su postojanja sitnih grešaka u vidu prslina, gasnih pora i drugih uključaka ili su odraz odbitaka ultrazvučnog talasa od neke geometrije zavarenog spoja.

Pojačanje kao izlazni parametar je pokazatelj koji govori, gde se prilikom ispitivanja lakše probija zvučni zid. Kod kontrolnog uzorka 0 i uzorka 1 registrovano je veće pojačanje na mestu zavarenog spoja nego na osnovnom materijalu, dok je kod uzorka 2 i 3 obrnuta situacija.

Sve u svemu, svi ispitani uzorci zadovoljavaju kriterijume koji su postavljeni pred zavarene spojeve železničkih šina dobijene aluminotermijskim postupkom, pre svega najveću dozvoljenu veličinu defekta (pora ili nemetalni uključak) od $5 \mathrm{~mm}$.

Tabela 2 Prikaz vrednosti izlaznog parametra pojačanja u području osnovnog materijala

\begin{tabular}{|c|c|c|c|}
\hline & Pojačanje & $\begin{array}{c}\text { Jedinica } \\
\text { mere }\end{array}$ & $\begin{array}{c}\text { Područje } \\
\text { uzorka }\end{array}$ \\
\hline $\begin{array}{c}\text { Kontrolni } \\
\text { uzorak 0 }\end{array}$ & 25 & $\mathrm{~dB}$ & $\begin{array}{c}\text { Osnovni } \\
\text { materijal }\end{array}$ \\
\hline Uzorak 3 & 25 & $\mathrm{~dB}$ & $\begin{array}{c}\text { Osnovni } \\
\text { materijal }\end{array}$ \\
\hline
\end{tabular}


Tabela 3 Prikaz vrednosti izlaznog parametra pojačanja u području metala šava

\begin{tabular}{|c|c|c|c|}
\hline $\begin{array}{c}\text { Redni } \\
\text { broj } \\
\text { uzorka }\end{array}$ & Pojačanje & $\begin{array}{c}\text { Jedinica } \\
\text { mere }\end{array}$ & $\begin{array}{c}\text { Područje } \\
\text { uzorka }\end{array}$ \\
\hline $\begin{array}{c}\text { Kontrolni } \\
\text { uzorak 0 }\end{array}$ & 27 & $\mathrm{~dB}$ & Metal šava \\
\hline Uzorak 3 & 24 & $\mathrm{~dB}$ & Metal šava \\
\hline
\end{tabular}

\subsection{Metalografska ispitivanja}

Izgled poliranih uzoraka prikazan je na slici 2. Kod svih uzoraka se vidi prisustvo uključaka u čvrstom stanju (nemetalnih uključaka) i gasnih uključaka (pora). Ove nepravilnosti su dozvoljene i uobičajene su kod zavarenih spojeva relativno velikih poprečnih preseka kao što su spojevi aluminotermijskim postupkom. Ovakvi rezultati su u skladu sa rezultatima ultrazvučnog ispitivanja.

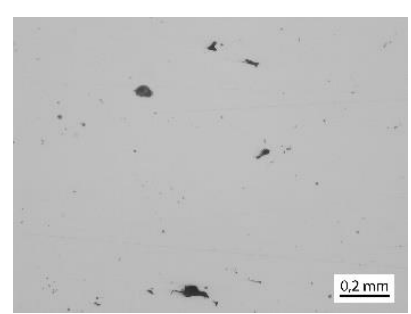

a)

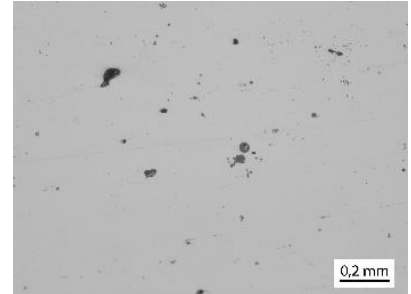

c)

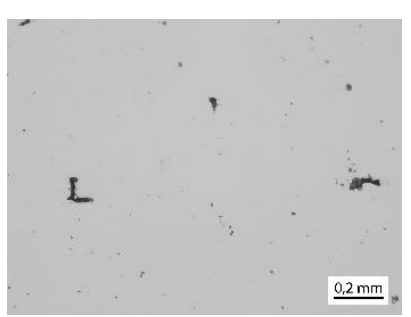

b)

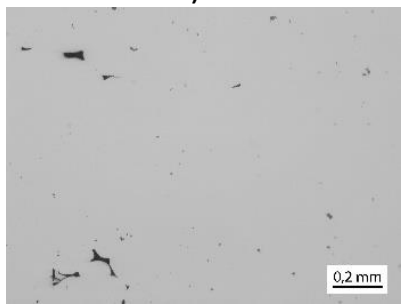

d)
Slika 2 Polirani uzorci: a) kontrolni uzorak 0, b) uzorak 1, c) uzorak 2, d) uzorak 3

Dobijene mikrostrukture u metalu šava pokazali su dominantno prisustvo perlita (tamna faza) uz manju količinu ferita (svetla faza). Ferit je kod svih uzoraka raspoređen oko prvobitnih austenitnih zrna u vidu dugih svetlih linija (alotriomorfni ferit-AF) kao i unutar prvobitnih austenitnih zrna (intragranularni idiomorfni ferit-IIF), slike $3 \mathrm{i}$ 4. Međutim, u blizini linije stapanja, unutar metala šava (slika 2), sadržaj obe vrste ferita je manji kod uzoraka sa nano česticama, naročito IIF.

Osim toga, vidi se da su prvobitna austenitna zrna, čije se konture vide na osnovu AF izdužena i da stvaraju tipičnu stubastu mikrostrukturu koja se javlja u metalu šava zavarenih spojeva.

Pravac ovih kristalita je jednak pravcu odvođenja toplote, ali je njihov rast u suprotnom smeru od smera odvođenja toplote.

U centralnom delu metala šava, IIF kod uzoraka zavarenih uz prisustvo nano čestica prisutan je u većoj količini nego u zoni prema liniji stapanja, ali je još uvek niži u odnosu na uzorak 0 .

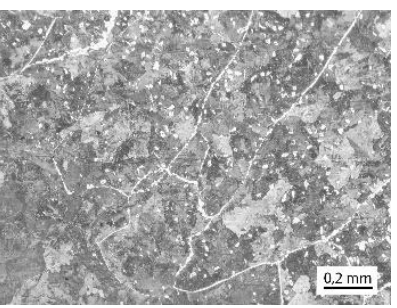

a)

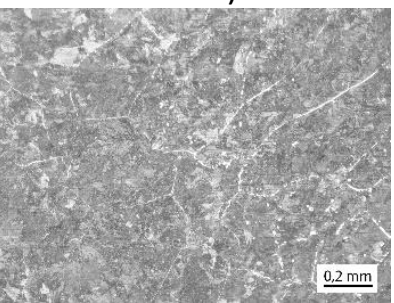

c)

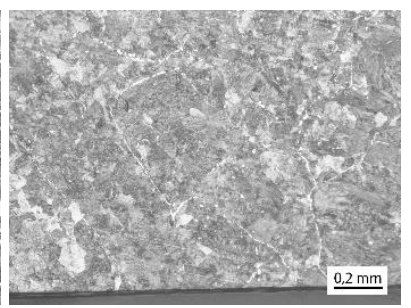

b)

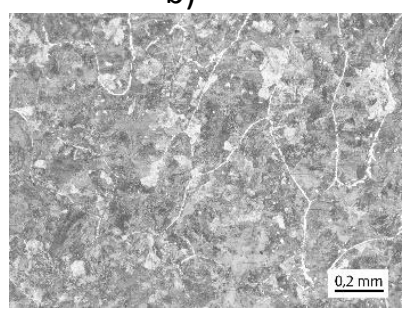

d)
Slika 3 Mikrostruktura prelazne zone; dole levo je ZUT, ostatak je metal šava: a) kontrolni uzorak 0,b) uzorak 1, c) uzorak 2, d) uzorak 3

Mikrostruktura ZUT-a je nepromenjena kod svih uzoraka, a isto važi i za osnovni materijal.



b)

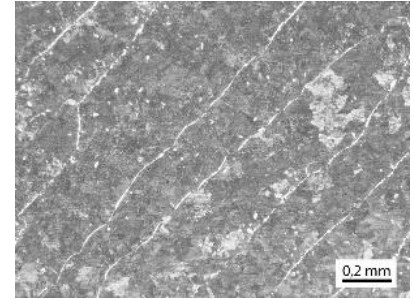

c)

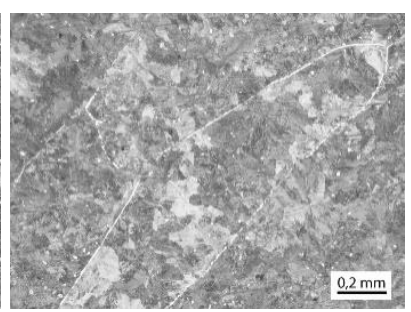

b)

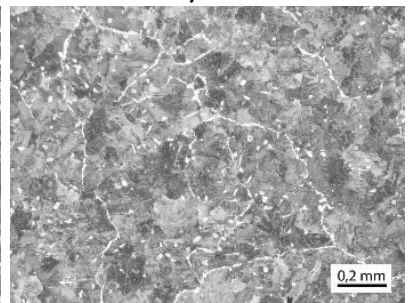

d)
Slika 4 Mikrostruktura centralnog dela metala šava: a) kontrolni uzorak 0, b) uzorak 1, c) uzorak 2, d) uzorak 3

\subsection{Ispitivanje tvrdoće}

Na osnovu dobijenih rezultata srednjih vrednosti tvrdoće može se konstatovati da je tvrdoća modifikovanih uzoraka $\mathrm{u}$ području metala šava značajno veća $u$ odnosu na nemodifikovani uzorak. Ovo povećanje je proporcionalno veće nego što je uzorak osnovnog materijala tvrđi $u$ odnosu na nemodifikovani materijal, dok su vrednosti u ZUT-u slične, tabela 4.

Najveće srazmerno povećanje tvrdoće je u zoni metala šava pored linije stapanja (MŠ́1 i MŠ2), upravo na mestu gde je primećeno smanjenje sadržaja IIF pri metalografskim ispitivanjem, slika 3. Najveće povećanje tvrdoće izmereno je na uzorku 1, sa najmanjim sadržajem nano čestica, gde je i sadržaj IIM najmanji. 
Tabela 4 Srednje vrednosti tvrdoće [HV] dobijenih rezultata ispitivanja

\begin{tabular}{|c|c|c|c|c|c|c|c|}
\hline $\begin{array}{c}\text { Redni } \\
\text { broj } \\
\text { uzork } \\
\mathbf{a}\end{array}$ & $\mathbf{O M}$ & $\begin{array}{c}\mathbf{Z U} \\
\mathbf{T}\end{array}$ & $\begin{array}{c}\text { MŠ } \\
\mathbf{- 1}\end{array}$ & $\mathbf{M S}$ & $\begin{array}{c}\mathbf{M S} \\
\mathbf{- 2}\end{array}$ & $\begin{array}{c}\mathbf{Z U} \\
\mathbf{T}\end{array}$ & $\mathbf{O M}$ \\
\hline $\mathbf{0}$ & 252 & 294 & 255 & 268 & 268 & 310 & 254 \\
\hline $\mathbf{1}$ & 255 & 309 & 302 & 288 & 301 & 295 & 258 \\
\hline $\mathbf{2}$ & 280 & 306 & 305 & 280 & 280 & 301 & 253 \\
\hline $\mathbf{3}$ & 266 & 291 & 296 & 278 & 299 & 315 & 293 \\
\hline
\end{tabular}

Sa gledišta mehaničkih osobina, svi modifikovani uzorci $(1,2,3)$ imaju bolje mehaničke osobine u odnosu na uzorak 0 . Optimalni uzorak je uzorak 1 , dobijen sa dodatim nanočesticama, a osnovni razlog je smanjen sadržaj ferita. S obzirom da ferit nastaje pre perlita, može se pretpostaviti da je prisustvo nano čestica uticalo na ograničavanje rasta ferita, tako da je u blizini linije topljenja došlo do gotovo potpunog zaustavljanja nastanka IIF kod uzoraka sa nano česticama.

Umesto nastanka IIF i AF, nastaje perlit. Za detaljnije objašnjavanje uticajnih fenomena korisno je nastaviti ispitivanja u pogledu zatezanja, savijanja i energije udara. Najveći efekat je prisutan kod uzorka sa najmanje dodatih nano čestica, verovatno kao posledica aglomeracije kod uzoraka sa više dodatih nano čestica.

\section{ZAKLJUČCI}

$\mathrm{Na}$ osnovu dobijenih rezultata, mogu se izvući sledeći zaključci:

- Dodavanje nanočestica nema negativan uticaj sa gledišta ultrazvučnog ispitivanja.

- Kao i kod kontrolnog uzorka, kod modifikovanih uzoraka u metalu šava nastaju pore i nemetalni uključci

- Mikrostruktura metala šava u zoni blizu linije topljenja ima manji sadržaj ferita, kako idiomorfnog intragranularnog, tako i alotriomorfnog.

- Tvrdoća u svim zonama je povećana, a najviše u metalu šava pored linije topljenja, što je posledica smanjenog sadržaja ferita.

- Najverovatniji uzrok nestanka ili smanjenja sadržaja ferita iz pojedinih zona jeste ograničavanje rasta usled prisustva nanočestica ili čestica, verovatno oksida.

- Najveći stepen ojačanja je dobijen kod uzorka sa najmanje dodatih nano čestica, najverovatnije zbog pojave aglomeracije tj. spajanja nano čestica kod uzoraka sa većim dodatkom nano čestica.

$\mathrm{Na}$ osnovu iznetog, može se zaključiti da unos nano čestica može da bude efikasan način ojačavanja aluminotermijskih zavarenih spojeva.

\section{ZAHVALNOST}

Rezultati prezentovani u ovom radu su realizovani u okviru projekta „Inovativni materijali i tehnologije spajanja“, Departmana za proizvodno mašinstvo, FTN, Novi Sad.

\section{LITERATURA}

[1] V. Palić, „Zavarivanje “, Novi Sad: Fakultet tehničkih nauka, 1987.

[2] M.J.M.M.Steenbergen, R.W. Van Bezooijen, ,Rail welds, Delfi University of Technology“, Id Consultancy, Netherlands, 2017.

[3] https://www.elektro-thermit.de/en/railjoining/thermitr-welding-processes/ (Pristupio 18.09.2021.)

[4] http://www.railsystem.net/thermit-welding/ (Pristupio -20.06 .2021 .)

[5] D. Ilić, ,Aluminotermijsko zavarivanje tračnica“, Završni rad, Sveučilište u Zagrebu fakultet strojarstva i brodogradnje, 2015.

[6] C.P. Londsdale, „Thermite rail welding: History, process developments, current practices and outlook for the $21^{\text {st }}$ century", Metallurgical Engineer Conrail Technical Services Labaratory, Altoona, USA, 2000. [7] https://rails.arcelormittal.com/types-rails/transportrails/european-standards/rail-s49-49e1 (Pristupio 21.09.2021)

[8] https://vts.edu.rs/wp-content/uploads/2017/11/4TEHNOLO\%C5\%A0KA-ISPITIVANJA.pdf (Pristupio 16.09.2021)

\section{Kratka biografija:}

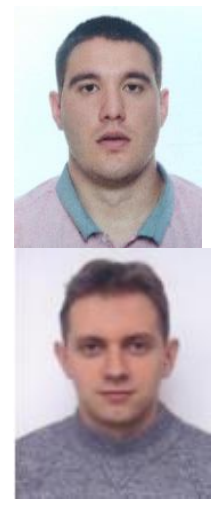

Ilija Đuranović rođen je u Novom sadu 1996. god. Diplomski rad na Fakultetu tehničkih nauka iz oblasti Proizvodno mašinstvo - Tehnologije spajanja odbranio je 2019.god.

Sebastian Baloš rođen je u Somboru 1974. god. Doktorirao je na Fakultetu tehničkih nauka 2010. god., a 2021. godine je biran u zvanje redovnog profesora iz oblasti Mašinsko inženjerstvo, tj. uže naučne oblasti Materijali i tehnologije spajanja. 